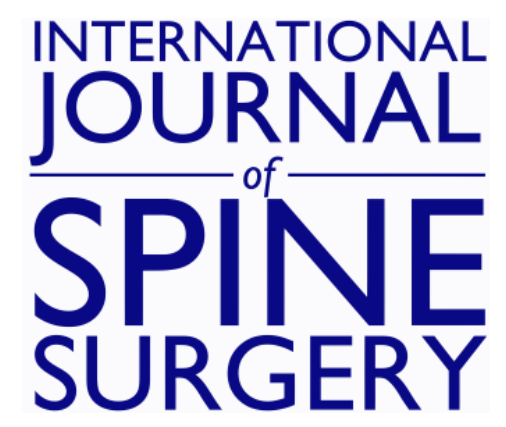

\title{
Transforaminal full-endoscopic lumbar discectomy in obese patients
}

Jun Seok Bae and Sang-Ho Lee

Int J Spine Surg 2016, 10 ()

doi: https://doi.org/10.14444/3018

http://ijssurgery.com/content/10/18

This information is current as of April 26, 2023.

Email Alerts Receive free email-alerts when new articles cite this article. Sign up at:

http://ijssurgery.com/alerts

The International Journal of Shing Surgerih 2397 Waterbury Circle, Suite 1,

Aurora, IL 60504, Phone: +1-630-375-1432

(C) 2016 ISASS. All Rights Reserved. 


\section{Transforaminal full-endoscopic lumbar discectomy in obese patients}

Jun Seok Bae, MD, Sang-Ho Lee, MD

Spine Health Wooridul Hospital

\section{Abstract}

\section{Background}

Obese patients are at risk of complications such as slower wound healing and increased infection rates after spinal surgery. Transforaminal full-endoscopic lumbar discectomy (ELD) has advantages over conventional microdiscectomy because it decreases perioperative complications and increases favorable clinical outcomes. No clinical studies have reported ELD in obese patients. The purpose of this study is to evaluate the clinical outcomes of transforaminal ELD in obese patients

\section{Methods}

Obesity is defined as a body mass index (BMI) of more than $30 \mathrm{~kg} / \mathrm{m} 2$. Our study included 21 obese patients and 27 normal BMI patients treated by posterolateral transforaminal ELD for radiating pain caused by a single-level lumbar disc herniation with more than 2 years of follow-up. Clinical chart reviews and telephone surveys were conducted. Clinical and functional outcomes using VAS and ODI, perioperative complications, and reherniation were evaluated.

Results

Overall clinical and functional outcomes were improved during postoperative follow-up evaluation. There were no immediate perioperative complications, such as infection or durotomy in both groups. In obese group, three patients had late reherniations. Of these, 2 patients had tolerable pain and showed good recovery with conservative treatment; 1 patient who had undergone ELD for recurrent disc herniation underwent open microdiscectomy. In control group, two patients had early reherniation and underwent open microdiscectomy and one patient with late reherniation showed good recovery with conservative treatment.

\section{Conclusion}

In select cases, ELD is an effective, safe, and minimally invasive technique for obese patients. It decreases perioperative morbidity and allows for both early mobilization and early return to work. Level of Evidence: level $3 \mathrm{~b}$.

KEYWORDS: TRANSFORAMINAL, ENDOSCOPIC, DISCECTOMY, OBESITY, COMPLICATION

VOLUME 10 ARTICLE 18 DOI: 10.14444/3018

\section{Introduction}

Increasing prevalence of obesity is a serious public health problem worldwide. Obesity has been implicated as a risk factor for lumbar disc degeneration. ${ }^{1}$ Obese patients are more likely to have radicular pain and neurologic disorders. ${ }^{2}$ Heliovaara et al. reported that heavy body mass were important contributors to lumbar disc herniation. ${ }^{3}$ Current surgical treatments in obese patients use a large incision to allow adequate visualization at depth; however, this causes paraspinal tissue injury, which is associated with perioperative morbidity. For morbidly obese patients who underwent decompressive spinal surgery, a complication rate as high as $50 \%$ has been reported. ${ }^{4}$ Transforaminal full-endoscopic lumbar discectomy (ELD) has been developed as a minimally invasive spinal surgery for soft disc herniation. ELD provides some benefits over open discectomy, such as less damage to paraspinal soft tissue, shorter hospital stays, and earlier return to work. ${ }^{5,6}$ This study was performed to evaluate outcomes after ELD in obese patients. We determined whether the potential advantages of ELD affect the incidence of perioperative complications and efficacy of surgery in obese patients. 


\section{Materials and Methods}

Obesity is defined in terms of BMI, which is calculated as body weight in kilograms divided by height in square meters. Patients with a BMI of $30 \mathrm{~kg} / \mathrm{m}^{2}$ or higher were considered to be obese and patients with a BMI of $18.5-22.9 \mathrm{~kg} / \mathrm{m}^{2}$ were considered to be normal. $^{7}$

A total of 143 patients underwent ELD between January 2011 and December 2011. Among them, 21 obese patients with BMI of more than $30 \mathrm{~kg} / \mathrm{m}^{2}$ were identified. For control group, we identified $27 \mathrm{pa}-$ tients with normal BMI between $18.5 \mathrm{~kg} / \mathrm{m}^{2}$ and 22.9 $\mathrm{kg} / \mathrm{m}^{2}$ with more than 2 years follow-up. Other patients with overweight or lack of follow-up were excluded. A retrospective study was performed by reviewing the clinical charts and preoperative admission sheets, which provided details of their height and weight.

The study participants were patients with unilateral leg pain associated with soft disc herniation, as determined by magnetic resonance imaging (MRI) and computed tomography (CT). Additionally, patients suffering from persistent pain after 6 weeks of conservative treatment, involving rest, analgesia, and physical therapy, were included. Physical examination showed a positive nerve root tension sign. The exclusion criteria were severe lumbar stenosis, spondylosis, spondylolisthesis, extraforaminal far lateral disc herniation, calcification, and foraminal spur or bony compression.

Clinical chart review and telephone survey was performed and patients with more than 2 years of follow-up were included. Clinical outcomes were assessed using the visual analogue scale (VAS; 0-10, with $0=$ no pain), and functional outcomes were scored according to the Oswestry Disability Index (ODI; 0-100\%), and return to work status. Additionally, presence of comorbidities, operating time, length of hospital stay, and perioperative complications were evaluated. During the postoperative follow-up period, MRI was performed when the patient complained of newly developed radiating pain. For all other patients without new symptoms, only a clinical follow-up was conducted.

\section{Statistical methods}

All data were entered into the SPSS statistical program (version 14.0K; SPSS Inc., Chicago, IL). Statistical tests included analysis of variance using the matched 2-sample $t$-test and Wilcoxon signed ranks test. Results were considered statistically significant if $\mathrm{p}$ was $<0.05$.

\section{Surgical technique}

The patient is placed on a radiolucent table in the prone position. His/her knee is flexed and draped aseptically. On the basis of anteroposterior and lateral fluoroscopic views, a skin marking is made to indicate the position of the midline and intervertebral disc. Next, after infiltration of local anesthetics, a 6-inch long, 18-gauge spinal needle is inserted transforaminally under fluoroscopic guidance. The needle tip is positioned at the midline. Intraoperative discography is performed by injecting a mixture of radio-opaque dye (Telebrix; Guerbet, France), indigo carmine (Carmine; Korea United Pharmaceutical, Yoenki, Korea), and normal saline in a 2:1:2 ratio. Indigo carmine stains the degenerated acidic nucleus blue, helping identify the herniated disc fragment. Upon successful insertion of the needle, a guidewire is inserted through the needle. The needle is withdrawn, and serial dilators and an obturator are introduced. A beveled working cannula is then introduced over the obturator. Next, the YESS endoscope with a working channel and 2 irrigation channels (Richard Wolf Surgical Instrument Co., Vernon Hills, IL) is introduced. Under endoscopic visualization, a bluestained annular surface and part of the disc material can be observed. Using a holmium:yttriumaluminum-garnet (Ho:YAG) laser and a bipolar radiofrequency coagulator $\left(\right.$ Ellman $^{\circledR}$; Ellman International, Hewlett, NY), annulectomy is performed. The blue stained herniated fragment can be visualized after this step. Then, the herniated disc material is meticulously removed using microforceps. Finally, a sterile dressing is applied with 1 point of subcutaneous suture. Patients are allowed to ambulate on the same postoperative day and are discharged as soon as they can independently walk. Postoperative MRI is performed immediately after operation or on the following day. Postoperative oral antibiotics and analgesics are recommended for 3-10 days following surgery. Additionally, a lumbar brace is worn for 3-14

Downloaded from http://ijssurgery.com/ by guest on April 26, 2023 
days, depending on the patient's condition. See Figure 1 and Figure 2.

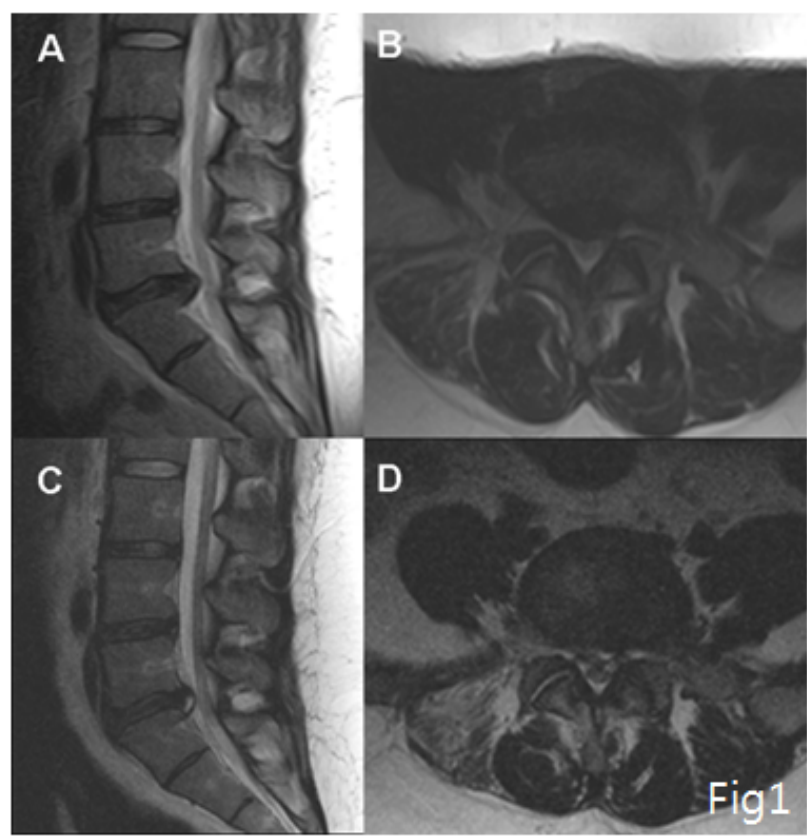

Fig. 1. Case illustration: A 25-year-old woman presenting with radiating pain on her right leg. Preoperative MRI scan showing lumbar disc herniation at the L5-S1 level, right. (A, B) Her BMI was $38.9 \mathrm{~kg} / \mathrm{m}^{2}$. Transforaminal ELD was performed, and the symptoms were alleviated. Postoperative MRI scan showing good decompression (C, D).

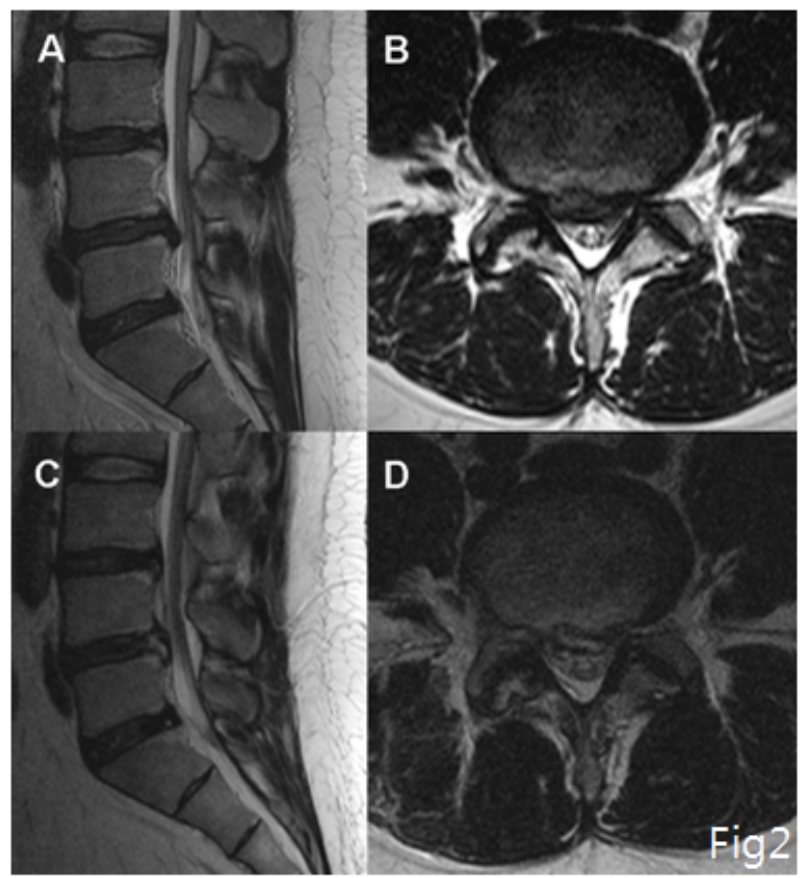

Fig. 2. Case illustration: A 56-year-old woman with arrhythmia, diabetes, and a lumbar disc herniation at the right L4-5 level. The herniation had migrated slightly downward (A, B). Her BMI was $32.5 \mathrm{~kg} / \mathrm{m}^{2}$.

Transforaminal ELD was performed, and symptoms were relieved. Postoperative MRI scan showing good decompression (C, D).

\section{Results}

Twenty-one obese patients of with more than 2 years of follow-up were enrolled in this study. The demographic and clinical data of obese patients and control group are summarized in Table 1.

The obese group comprised 14 (66.7\%) men and 7 (33.3\%) women, with a mean age of 37.8 years (range, 20-60 years). Their mean BMI was $32.9 \mathrm{~kg} / \mathrm{m}^{2}$ (range, $30.1-38.9 \mathrm{~kg} / \mathrm{m}^{2}$ ). Five (31.3\%) of the sixteen patients had comorbidities such as hypertension, heart disease, diabetes, and fatty liver. The control group comprised 12 (44.4) men and 15 (55.6\%) women, with a mean age of 38.1 years (range, 17-75 years). Their mean BMI was $20.8 \mathrm{~kg} / \mathrm{m}^{2}$ (range, $19.2-22.8 \mathrm{~kg} / \mathrm{m}^{2}$ ). The mean duration of follow-up was 28.3 months (range, 24-43 months). Two (7.4\%) of 27 patients had comorbitities such as hyperthyroidism and fatty liver.

The affected spinal levels were mostly L4-5 and L5-S1 level in both groups. In terms of herniation

\begin{tabular}{|c|c|c|}
\hline & \multicolumn{2}{|r|}{ Overall } \\
\hline & Obesity & Control \\
\hline Number of patient & 21 & 27 \\
\hline Gender (males/females) & $14 / 7$ & $12 / 15$ \\
\hline Average age (years) (range) & 37.8 & 38.1 \\
\hline BMI (kg/m2) (range) & 32.9 & 20.8 \\
\hline Preop. Sx duration (weeks) & 11.1 & 14.5 \\
\hline Mean FU duration (months) & 31.9 & 28.3 \\
\hline \multicolumn{3}{|l|}{ Discectomy level (cases) } \\
\hline L2-3 & 2 & 0 \\
\hline L3-4 & 1 & 0 \\
\hline L4-5 & 13 & 21 \\
\hline L5-S1 & 5 & 6 \\
\hline \multicolumn{3}{|l|}{ Heniation type } \\
\hline Contained/non-contained & $12 / 9$ & $11 / 16$ \\
\hline Recurrent herniation ${ }^{*}$ & 5 & 5 \\
\hline
\end{tabular}
herniation after conventional microdiscectomy. 
microdiscectomy is that the entire procedure can be performed under local anesthesia. Thus, with respect to comorbidities in obese patients, surgeons can avoid complications associated with general anesthesia. In our study population, we treated patients with dilated cardiomyopathy, arrhythmia, and aortic aneurysm without the occurrence of any lifethreatening complications. ELD permits early mobilization and early return to work. Kahanovitz et al. reported an approximately $30 \%$ decrease in trunk muscle strength after discectomy operation. ${ }^{14}$ However, there was no paraspinal muscle trauma during ELD. The ultimate goal of surgical treatment for disc herniation is early return to function of the patient. ELD has advantages in reducing postoperative recovery time and promoting pain-free status. Many other authors reported treatment of obese patients with minimally invasive surgical techniques. Their results are in agreement with ours: a less invasive approach helps minimize infections and wound-related complications. ${ }^{15-17}$ Cole et al. ${ }^{17}$ reported a study on 32 obese patients with lumbar disc herniation treated by the METRx tubular retractor system. Using this minimally invasive discectomy technique, they reported a favorable clinical outcome and a $12.5 \%$ overall complication rate in a study population that showed 2 recurrent disc herniations requiring reoperation and no infectious complications. Interestingly, the most common complication was incidental durotomy, found in $9.4 \%$ of the patients. This could be related to the greater working distance necessary in obese patients. Park et al. also reported 2 adverse incidental durotomies during minimally invasive discectomy or decompressive laminectomy. ${ }^{16}$ These previous studies demonstrate the effectiveness of minimally invasive discectomy, which is favorable for obese patients because it minimizes incision length and infectious complications.

There were no cases of incidental durotomy in present study. The endoscopic view during ELD is independent of the working distance between skin and intervertebral disc. Ahn et al. reported that ELD caused only $1.1 \%$ of symptomatic dural tears, ${ }^{18}$ whereas the incidence after conventional spinal surgery ranged from $3.1 \%$ to $14 \% .^{19,20}$ With accurate information and proper technical considerations, durotomy during ELD can be prevented. In our study, we treat- ed 5 cases of recurrent disc herniations after open microdiscectomy, and there were no perioperative complications. One of the patients underwent reoperation because of symptomatic reherniation. Ahn et al. reported the effectiveness of ELD for recurrent disc herniation, and they found no case of durotomy. ${ }^{21}$

In the present study, obese group had $3(14.3 \%)$ cases of symptomatic reherniations with only 1 (4.7\%) patient receiving open microdiscectomy at the same level before requiring reoperation. On the other hand, control group showed 2 cases of early reherniation and 1 case of late reherniation, of which 2 (7.4\%) early reherniations underwent open microdiscectomy. The incidence of reherniation of obese group in the present study seems to be relatively high compared with that in previous reports on conventional microdiscectomy, which ranged from $2 \%$ to $10.4 \% .{ }^{22,23}$ Kim et al. speculated that the high rate of recurrence associated with ELD is due to the relatively decreased decompression caused during piecemeal removal of disc material and the possibility of hidden fragments being overlooked. However, we think that the study population should be considered when interpreting the result. Because patients with higher BMI exhibited higher disc recurrence rates,${ }^{24}$ the relative high recurrence rate in obese might not be limited to the technical difficulties of ELD. In fact, there was only 1 case $(6.3 \%)$ of a revision operation in obese group because of reherniation but control group had 2 cases $(7.4 \%)$ of revision operations. Cole et al. ${ }^{17}$ also reported that 2 of $32(6.3 \%)$ obese patients required reoperation for reherniation after being treated with minimally invasive lumbar microdiscectomy, and one patient required fusion because of postoperative instability.

The incidence of complications after conventional spinal surgery is generally reported to be higher in obese patients than in normal weight populations, especially in terms of wound problems and infections. ${ }^{4,25-29}$ Although the overall clinical outcome in obese patients after lumbar spine surgery is not inferior to that in the normal weight population, ${ }^{4,27,30,31}$ wound infection rates are higher in obese patients, with a wide range of incidence rates reported. ${ }^{4,25,27,29,32}$ Additionally, many authors reported obesity as a risk

Downloaded from http://ijssurgery.com/ by guest on April 26, 2023 
factor for surgical wound infection. ${ }^{28,32}$ We assume that the increased complication rates in obese patients can be attributed to technical difficulties associated with a deep surgical field; operations taking more time, thus increasing the chances of contamination; more paraspinal muscles trauma; and necrosis of the back muscles and subcutaneous tissue because of more forceful retraction during surgery. Wound dehiscence is also found in obese patients, probably because of increased tension on the fascial edges at the time of wound closure and/or hematoma/seroma that creates internal tension on sutured incisions. The infectious complication rate of ELD is very low, ${ }^{33}$ and there were no infectious complications in the present study population.

Although ELD requires steep learning curve, it seems to be stable and acceptable with proper training and suitable patient selection. Observation of experienced surgeons and attending workshops for training period could be helpful for unexperienced surgeon. ${ }^{34}$ According to previous reports, first 20 cases of learning curves seems to be required for this. 34,35

The limitations of this study are related to its retrospective design. There are 5 patients for whom we have no follow-up data, which lessens the sincerity of the present cohort. Another is that we only reviewed clinical charts and operative records. If any complication was not noted in the chart, it was missed by this study's assessment methods. Postoperatively, routine MRI follow-up has not performed in asymptomatic patients, so we were not able to convince any asymptomatic reherniation in this cohort. However, after treatment of disc herniation, long-term improvement in a patient's symptoms occurs with or without resolution of the hernia. ${ }^{36}$ On the basis of these results, we think that clinical outcomes are more important for follow-up after discectomy.

To the best of our knowledge, this is the first study on ELD in obese patients. It is more advantageous than conventional microdiscectomy in terms of perioperative infection and wound complication, in addition to its favorable clinical outcomes. Obese patients with severe comorbidities, who are at risk from general anesthesia, can be treated with ELD. Consider- ing the increasing prevalence of obesity and elderly patients, ELD could be a good alternative minimally invasive technique for surgical treatment of radiculopathy caused by lumbar disc herniation.

\section{Conclusion}

Although the frequency of reherniation was higher in our study, the results demonstrated favorable clinical outcomes after transforaminal ELD in obese patients. It is an effective, safe, and minimally invasive technique for select cases of obese patients. It appears to benefit obese patients because of the fullendoscopic approach, almost no tissue trauma, and no adverse events associated with general anesthesia.

\section{References}

1. Liuke M, Solovieva S, Lamminen A, et al. Disc degeneration of the lumbar spine in relation to overweight. Int J Obes (Lond). 2005;29(8):903-908.

2. Fanuele JC, Abdu WA, Hanscom B, Weinstein JN. Association between obesity and functional status in patients with spine disease. Spine (Phila Pa 1976). 2002;27(3):306-312.

3. Heliovaara M. Body height, obesity, and risk of herniated lumbar intervertebral disc. Spine (Phila Pa 1976). 1987;12(5):469-472.

4. Telfeian AE, Reiter GT, Durham SR, Marcotte P. Spine surgery in morbidly obese patients. J Neurosurg. 2002;97(1 Suppl):20-24.

5. Maroon JC. Current concepts in minimally invasive discectomy. Neurosurgery. 2002;51(5 Suppl):S137-145.

6. Kambin P, Brager MD. Percutaneous posterolateral discectomy. Anatomy and mechanism. Clin $\mathrm{Or}$ thop Relat Res. 1987(223):145-154.

7. Health NIo. Clinical Guidelines on the Identification, Evaluation, and Treatment of Overweight and Obesity in Adults--The Evidence Report. National Institutes of Health. Obes Res. 1998;6 Suppl 2:51S-209S.

8. Lee SH, Kang HS, Choi G, et al. Foraminoplastic ventral epidural approach for removal of extruded herniated fragment at the L5-S1 level. Neurol Med Chir (Tokyo). 2010;50(12):1074-1078.

9. Choi G, Lee SH, Lokhande P, et al. Percutaneous

Downloaded from http://ijssurgery.com/ by guest on April 26, 2023 
endoscopic approach for highly migrated intracanal disc herniations by foraminoplastic technique using rigid working channel endoscope. Spine (Phila Pa 1976). 2008;33(15):E508-515.

10. Lee S, Kim SK, Lee SH, et al. Percutaneous endoscopic lumbar discectomy for migrated disc herniation: classification of disc migration and surgical approaches. Eur Spine J. 2007;16(3):431-437.

11. Choi G, Lee SH, Raiturker PP, Lee S, Chae YS. Percutaneous endoscopic interlaminar discectomy for intracanalicular disc herniations at L5-S1 using a rigid working channel endoscope. Neurosurgery. 2006;58(1 Suppl):ONS59-68; discussion ONS59-68. 12. Hermantin FU, Peters T, Quartararo L, Kambin P. A prospective, randomized study comparing the results of open discectomy with those of videoassisted arthroscopic microdiscectomy. J Bone Joint Surg Am. 1999;81(7):958-965.

13. Ruetten S, Komp M, Merk H, Godolias G. Fullendoscopic interlaminar and transforaminal lumbar discectomy versus conventional microsurgical technique: a prospective, randomized, controlled study. Spine (Phila Pa 1976). 2008;33(9):931-939.

14. Kahanovitz N, Viola K, Gallagher M. Longterm strength assessment of postoperative diskectomy patients. Spine (Phila Pa 1976).

1989;14(4):402-403.

15. Senker W, Meznik C, Avian A, Berghold A. Perioperative morbidity and complications in minimal access surgery techniques in obese patients with degenerative lumbar disease. Eur Spine J. 2011.

16. Park P, Upadhyaya C, Garton HJ, Foley KT. The impact of minimally invasive spine surgery on perioperative complications in overweight or obese patients. Neurosurgery. 2008;62(3):693-699; discussion 693-699.

17. Cole JSt, Jackson TR. Minimally invasive lumbar discectomy in obese patients. Neurosurgery. 2007;61(3):539-544; discussion 544.

18. Ahn Y, Lee HY, Lee SH, Lee JH. Dural tears in percutaneous endoscopic lumbar discectomy. Eur Spine J. 2011;20(1):58-64.

19. Cammisa FP, Jr., Girardi FP, Sangani PK, Parvataneni $\mathrm{HK}$, Cadag $S$, Sandhu HS. Incidental durotomy in spine surgery. Spine (Phila Pa 1976).

2000;25(20):2663-2667.

20. Wang JC, Bohlman HH, Riew KD. Dural tears secondary to operations on the lumbar spine. Management and results after a two-year-minimum follow-up of eighty-eight patients. J Bone Joint Surg Am. 1998;80(12):1728-1732.

21. Ahn Y, Lee SH, Park WM, Lee HY, Shin SW, Kang HY. Percutaneous endoscopic lumbar discectomy for recurrent disc herniation: surgical technique, outcome, and prognostic factors of 43 consecutive cases. Spine (Phila Pa 1976). 2004;29(16):E326-332. 22. Faulhauer K, Manicke C. Fragment excision versus conventional disc removal in the microsurgical treatment of herniated lumbar disc. Acta Neurochir (Wien). 1995;133(3-4):107-111.

23. Striffeler H, Groger U, Reulen HJ. "Standard" microsurgical lumbar discectomy vs. "conservative" microsurgical discectomy. A preliminary study. Acta Neurochir (Wien). 1991;112(1-2):62-64.

24. Kim JM, Lee SH, Ahn Y, Yoon DH, Lee CD, Lim ST. Recurrence after successful percutaneous endoscopic lumbar discectomy. Minim Invasive Neurosurg. 2007;50(2):82-85.

25. Yadla S, Malone J, Campbell PG, et al. Obesity and spine surgery: reassessment based on a prospective evaluation of perioperative complications in elective degenerative thoracolumbar procedures. Spine J. 2010;10(7):581-587.

26. Shamji MF, Parker S, Cook C, Pietrobon R, Brown C, Isaacs RE. Impact of body habitus on perioperative morbidity associated with fusion of the thoracolumbar and lumbar spine. Neurosurgery. 2009;65(3):490-498; discussion 498.

27. Gepstein R, Shabat S, Arinzon ZH, Berner Y, Catz A, Folman Y. Does obesity affect the results of lumbar decompressive spinal surgery in the elderly? Clin Orthop Relat Res. 2004(426):138-144.

28. Olsen MA, Mayfield J, Lauryssen C, et al. Risk factors for surgical site infection in spinal surgery. $J$ Neurosurg. 2003;98(2 Suppl):149-155.

29. Wimmer C, Gluch H, Franzreb M, Ogon M.

Predisposing factors for infection in spine surgery: a survey of 850 spinal procedures. J Spinal Disord. 1998;11(2):124-128.

30. Andreshak TG, An HS, Hall J, Stein B. Lumbar spine surgery in the obese patient. J Spinal Disord. 1997;10(5):376-379.

31. Hanigan WC, Elwood PW, Henderson JP, Lister JR. Surgical results in obese patients with sciatica. 
Neurosurgery. 1987;20(6):896-899.

32. Massie JB, Heller JG, Abitbol JJ, McPherson D, Garfin SR. Postoperative posterior spinal wound infections. Clin Orthop Relat Res. 1992(284):99-108. 33. Choi KB, Lee CD, Lee SH. Pyogenic spondylodiscitis after percutaneous endoscopic lumbar discectomy. J Korean Neurosurg Soc. 2010;48(5):455-460.

34. Lee DY, Lee SH. Learning curve for percutaneous endoscopic lumbar discectomy. Neurol Med Chir (Tokyo). 2008;48(9):383-388; discussion 388-389.

35. Wang H, Huang B, Li C, et al. Learning curve for percutaneous endoscopic lumbar discectomy depending on the surgeon's training level of minimally invasive spine surgery. Clin Neurol Neurosurg. 2013;115(10):1987-1991.

36. Fraser RD, Sandhu A, Gogan WJ. Magnetic resonance imaging findings 10 years after treatment for lumbar disc herniation. Spine (Phila Pa 1976).

1995;20(6):710-714.

\section{Disclosures and COI}

The authors declare no relevant disclosures with respect to this manuscript.

\section{Corresponding Author}

Sang-Ho Lee, MD, PhD, Wooridul Hospital, 445

Hankdong-ro, Gangnam-gu, Seoul, Korea. drsangholee@wooridul.co.kr.

Published 4 May 2016.

This manuscript is generously published free of charge by ISASS, the International Society for the Advancement of Spine Surgery. Copyright @ 2016 ISASS. To see more or order reprints or permissions, see http://ijssurgery.com. 